\title{
Diálogo com mediadores de Museus de Ciência
}

\author{
Dialogues with mediators in Science Museums
}

\author{
Maria Margareth Cancian Roldi ${ }^{1}$ \\ https://orcid.org/0000-0002-8359-7433 \\ Mirian do Amaral Jonis Silva ${ }^{1}$ \\ https://orcid.org/0000-0002-3838-8798 \\ Carlos Roberto Pires Campos ${ }^{1}$ \\ https://orcid.org/0000-0001-7708-4597
}

Resumo: Analisamos como a mediação humana ocorre nas visitas monitoradas do Instituto Nacional da Mata Atlântica (INMA), localizado em Santa Teresa, ES, considerando o ponto de vista dos mediadores acerca de seu papel na mediação. Os dados produzidos decorreram das transcrições das gravações em áudio das entrevistas realizadas com os mediadores e dos registros recolhidos durante as observações. Constatamos um forte apelo, por parte dos mediadores, na reprodução do roteiro que o INMA oferece, buscando adaptá-lo à série/idade dos visitantes. O anseio por uma formação adequada ficou marcante durante as entrevistas, talvez reforçado pelo não entendimento do real papel de um mediador de museus. O INMA tem potencial para se tornar um espaço educativo cujos mediadores sejam capazes de atrair e motivar os visitantes. Para tanto, precisam conscientizar-se da importância de sua função social na aprendizagem e de seu papel no desempenho da mediação.

Palavras-chave: Museus de ciência. Mediação humana. Formação de mediadores.

\begin{abstract}
We analyze how human mediation occurs in the monitored visits to the Instituto Nacional da Mata Atlântica-INMA, located in Santa Teresa, ES, considering the mediators' point of view of their roles in mediation, as well as their anxieties. Data were collected from transcriptions of audio recordings of the interviews with the mediators, and from systematic observations. We noticed a strong interest among mediators in the reproduction of the script that INMA offers as well as attempts to adapt it to visitors' profiles. The yearning for training was remarkably verified during the interviews, perhaps reinforced by the lack of understanding of a museum mediator's real role. INMA has the potential to become an educational space, in which mediators can attract and motivate the visitor to seek answers, so they need to be aware of the importance of their social function and their role in the mediation process.
\end{abstract}

Keywords: Science museums. Human mediation. Education of museum mediators.

\footnotetext{
${ }^{1}$ Instituto Federal de Educação, Ciência e Tecnologia do Espírito Santo (IFES), Programa de Pós-graduação em Educação em Ciências e Matemática (Educimat), Vitória, ES, Brasil. E-mail: carlosr@ifes.edu.br
} 


\section{Introdução}

Os museus de ciência na atualidade podem ser considerados parceiros na educação em ciências, se pensarmos nas variadas possibilidades asseguradas pela relação museu-escola e se visualizarmos a educação científica oferecida pelos museus e centros de ciência para a formação científica dos visitantes. Segundo Gomes e Cazelli (2014), das transformações verificadas na história contemporânea dos museus, é possível destacar o aumento de sua função educativa e a consolidação de setores próprios para cumprir essa função, demandando por profissionais qualificados para atuar em tais espaços. No entender de Mora (2007), nesse cenário, principalmente nos museus de ciência, a experiência do visitante precisa se distanciar da observação passiva, devendo caminhar rumo a um processo de questionamento, por meio do qual o visitante se transforme em um produtor de ideias. Assim, confere-se uma importância maior "ao visitante individualizado, que tem de ser ensinado a observar, para que, com isso, consiga descobrir, analisar e interpretar, ao seu passo, segundo suas necessidades e interesses" (MORA, 2007, p. 22).

Neste sentido, merecem destaque as ações desenvolvidas em museus e centros de ciências e seus agentes condutores, visto que a realidade da oralidade é comum nesses espaços. Tais profissionais atuam como peças centrais nos processos de educação e de mediação com o público, configurando-se, ainda, como importantes agentes em favor do aprimoramento e do aperfeiçoamento das ações educativas nos museus de ciência. Pensando nos profissionais que atuam nos museus de ciência e tomando por base os dados analisados nesse estudo, destacamos uma prática de mediação humana que se preocupa em possibilitar aos visitantes a habilidade de relacionar o acervo museológico aos conhecimentos científicos. Argumentamos em favor de uma abordagem contextualizada, que pode levar o visitante a querer buscar respostas. Mediante tal perspectiva, o artigo analisa como a mediação humana ocorre nas visitas monitoradas do Instituto Nacional da Mata Atlântica (INMA), localizado em Santa Teresa, ES, considerando o ponto de vista dos mediadores de qual seja seu papel na mediação e quais os anseios dos mediadores em questão.

\section{Mediação humana em museus de ciências}

Davallon (2007) compreende a mediação como uma ação que traz a presença de um terceiro componente, cumprindo um papel de intermediário entre os outros dois elementos, cuja ação ocasiona algum tipo de impacto sobre os destinatários. Nessa perspectiva, Gomes e Cazelli (2016) afirmam que a mediação implica mudança e não apenas transferência de uma mensagem, vez que a comunicação ocorre pela operação do terceiro componente. Para as autoras, a mediação em museus circunda eminentemente diversos níveis de diálogo: "entre o público e as exposições; entre os sujeitos e o saber; entre a arte, a ciência, a história e a sociedade" (GOMES; CAZELLI, 2016, p. 4). Outro autor que discute o conceito de mediação em seus amplos matizes é Almeida (2008, p. 2), para quem

[...] a ideia de mediação envolve coisas muito diferentes entre si, que abarcam desde as velhas concepções de 'atendimento ao usuário', passando pela atividade de um agente cultural em uma dada instituição - museu, 
biblioteca, arquivo, centro cultural - até a construção de produtos destinados a introduzir o público num determinado universo de informações e vivências (arte, educação, ecologia, por exemplo), chegando à elaboração de políticas de capacitação ou de acesso às tecnologias de informação e comunicação etc.

No pensar de Gomes e Cazelli (2016), os mediadores de museus recebem várias denominações em diversos países. As autoras ponderam que a existência de diversas denominações para esses profissionais relaciona-se com vários pontos de vista acerca do papel que um mediador de museus deve desempenhar. Nesse ponto, as autoras dialogam com Almeida (2008) que também compreende a noção de mediação com o papel que vai desde a apresentação até a importante função de atuar como interlocutor entre a ciência em exposição e o grande público, sendo múltipla a natureza dessa função. Assim, esses mediadores são aqueles que realizam as visitas guiadas, atuam como agentes culturais de setores educativos dos museus ou ainda como os profissionais que se encontram dispostos entre as exposições e o público, os quais estão à disposição do visitante para esclarecimentos de dúvidas e para estabelecer a comunicação da ciência (BRAGA, 2012).

Os mediadores dos museus de ciência são importantes nessas instituições, sobretudo porque esses espaços normalmente oferecem atividades que necessitam de mediação e, segundo Marandino (2008, p. 28), "os mediadores ocupam papel central, dado que são eles que concretizam a comunicação da instituição com o público e propiciam o diálogo com os visitantes acerca das questões presentes no museu, dando-lhes novos significados”. As autoras alegam não ser forte demais afirmar que o mediador é a voz da instituição, ainda que nem sempre ele tenha plena consciência do que isso representa. Martín-Barbero (1997) acrescenta que as mediações são ferramentas que têm o poder de modificar o sentido de algo. Logo, deve-se dar a devida importância às mediações em museus de ciência, pois esse poder de transformação revela-se com um instrumento de grande força na divulgação científica e na circulação dos resultados das pesquisas realizadas nesses espaços, promovendo o debate científico e instigando novos talentos rumo às pesquisas científicas.

No entender de Johnson (2007), espera-se que os mediadores ensinem por intermédio da experiência e da prática, sempre que possível. Para o autor, os mediadores devem explicar a ciência para aqueles que a desejam, ou seja, os mediadores devem saber como formular a pergunta correta a fim de detalhar e enriquecer a experiência do visitante. No entanto, existem níveis de explicação que podem ser oferecidos para a mesma exposição, nesse sentido, o mediador deve ter o cuidado para perceber como irá conduzir a mediação. Pensando nas visitas escolares em museus, em muitas ocasiões, um conteúdo já visto na escola aparece em um novo contexto ou é apresentado de forma distinta, criando certa dificuldade de entendimento. Novamente se faz importante a figura do mediador para transpor essas possíveis dificuldades.

Normalmente os mediadores de museu são jovens estudantes do ensino médio e do ensino superior de diversas áreas do conhecimento, no entanto, quando tratamos de museus de ciência, sobressaem-se os estudantes de biologia, química, física, geografia e áreas afins (CAFFAGNI, 2010). Frequentemente são estagiários ou colaboradores sem vínculo empregatício de longo prazo, razão pela qual há uma grande rotatividade nas equipes, o que demanda a realização periódica de atividades de formação. Assim, é essencial na mediação em museus 
o aperfeiçoamento teórico e prático da formação dos profissionais envolvidos nessa atividade.

Rodari e Merzagora (2007, p. 9) pontuam duas observações, as quais devem ser consideradas na formação dos mediadores de museus:

$1^{a}$ é necessário deixar de lado um modelo de comunicação da ciência moldado sobre suposições do que o público não sabe e passar para um modelo que tem como ponto de partida o que o público sabe; $2^{\circ}$ uma comunicação na qual apenas um dos atores amplia seu conhecimento ou está aberto à mudança não é útil para expandir nossa compreensão de mundo.

Discutindo sobre as observações de Rodari e Merzagora (2007), observamos que normalmente o mediador de museus repete um roteiro elaborado antecipadamente, o que revela a constatação de uma mediação por repetição, partindo do pressuposto de que o visitante não tem conhecimento algum sobre a exposição apresentada. Para alguma mudança, faz-se necessário um profundo conhecimento do conteúdo da exposição e de sua concepção, bem como uma formação específica para uma mediação a partir dos questionamentos do visitante. Faz-se necessária também a preparação para o improviso e para dialogar sobre ciência. Rodari e Merzagora (2007) entendem que essa maneira de mediação é uma via de mão dupla, pois quando se abrem as portas para o diálogo, ambos, mediadores e visitante, podem construir diversos tipos de conhecimento.

No entanto, muitas vezes, pelo fato de os mediadores estarem acostumados com os discursos prontos, eles podem sentir dificuldade em deixar fluir a mediação a partir das dúvidas do visitante. É importante ressaltar que os mediadores dos museus de ciência têm potencial para a realização dessas mudanças, uma vez que esses espaços proporcionam ambientes instigantes, com potencial investigativo, próprios da ciência. Como contraponto a essa afirmação, Rodari e Merzagora (2007, p. 9) afirmam que os museus de ciências "se comportam como qualquer outra mídia, como emissores que oferecem informações a uma audiência indiferenciada e passiva, em vez de tirar vantagem da possibilidade de estabelecer uma conversação com seus visitantes."

Sobre a formação dos mediadores, Rodari e Merzagora (2007) esclarecem que esses sujeitos têm potencial para a realização de uma mediação a partir de questionamentos, porquanto eles são os únicos que podem dialogar diretamente com o público, contato que não pode ser substituído por qualquer mídia, devido às especificidades que cada visitante vai demandar durante a mediação. Novamente percebemos a importância do papel dos mediadores em museus, vez que eles que acolhem os questionamentos dos visitantes, que podem variar dependendo do público.

Rodari e Merzagora (2007), pesquisando sobre a diversidade de mediadores de museus de ciência europeus, verificaram que, embora todos concordem com a importância da mediação humana, há pouco investimento na formação desses sujeitos, negando-lhes a possibilidade de um desenvolvimento profissional e mesmo de uma identidade, como um profissional qualificado para executar a função considerada essencial na configuração educacional mais ampla que os museus adquiriram. Nessa pesquisa, os autores perceberam alguns aspectos importantes sobre a formação dos mediadores em museus de ciência, quais sejam: (1) dificilmente a capacitação inclui aporte teórico sobre educação não formal bem como a teoria 
da comunicação da ciência; (2) dificilmente ficam sabendo sobre o que seus pares de outros países ou mesmo de outros museus estão fazendo; (3) não são envolvidos na idealização e planejamento das atividades que sua instituição oferece ao público. Não recebem formação direcionada aos estudos sobre visitação e avaliação; (4) não são capacitados para explorar os objetivos, o impacto e os resultados do seu trabalho; (5) não são preparados para coletar e analisar as reações do público; (6) raramente o museu reúne o conhecimento que os mediadores têm acerca do público e sua avaliação das estratégias de comunicação.

Mora (2007) expõe que os mediadores devem possuir entendimento profundo dos objetivos das equipes que idealizaram as exposições para conseguirem adequar suas interlocuções às diferentes idades, níveis de conhecimento e de interesse do público visitante. A autora ressalta que para alcançar êxito, os mediadores devem receber formação continuada oferecida pelo próprio museu, de modo a sentirem-se aptos para atuar na instituição e consequentemente conseguirem personalizar sua função.

Queiroz (2013) reforça essa ideia, quando considera a função do mediador passível de inúmeras interposições durante todo seu tempo de profissão. A autora destaca que a formação inicial, e continuada, dos mediadores de museus não deve ser restrita, apesar de importante, aos aspectos técnicos. "Se queremos modificar um conjunto de práticas dos mediadores de museus, solidificadas na ausência do diálogo, é necessário que nossos mediadores se formem para agirem dialogicamente com o público" (QUEIROZ, 2013, p. 151).

Gomes e Cazelli (2014) estudando a formação oferecida pelo Museu Espaço Ciência Viva (ECV) e do Museu de Astronomia e Ciências Afins (Mast) revelam que os dois museus apresentam semelhanças na formação ofertada aos seus mediadores no que diz respeito à estruturação das ações empreendidas durante a capacitação. Tais semelhanças incluem um curso de rápida duração oferecido no início de cada ano, bem como variadas ações de formação em serviço. As autoras apontam que a formação inicial consiste em prover aos mediadores inexperientes instrumentos básicos para a execução do trabalho, com abordagem teórico-prática, e que, em tais cursos, são apresentadas as atividades que os museus desenvolvem com o público, junto a referenciais teóricos relacionados às atividades, com foco na educação em museus.

Gomes e Cazelli (2014, p. 11) expõem que, após esses cursos iniciais, a formação ocorreu de modo contínuo das seguintes formas: "observação da atuação de mediadores experientes; capacitações pontuais para atividades específicas; reuniões periódicas; estudo orientado; participação em cursos externos, palestras e seminário". As autoras observaram na formação de mediadores do ECV uma tendência forte aos saberes disciplinares tanto no direcionamento da atividade quanto no perfil dos responsáveis pela formação, visto que, entre as atividades desenvolvidas, somente uma não estava relacionada aos conceitos de química, física ou biologia, temas normalmente abordados nas atividades de divulgação cientifica da instituição. As autoras argumentam que esse tipo de formação ocorre devido às finalidades dos museus estudados, relacionado à divulgação da ciência, razão pela qual demandam um vasto conhecimento dos temas tratados e a capacidade de os mediadores responderem aos questionamentos diversificados, e imprevistos, por parte dos visitantes.

Gomes e Cazelli (2014) pontuam que no Mast os saberes disciplinares não apresentaram tanto destaque na formação dos mediadores. A formação, segundo as autoras, ateve-se a uma perspectiva mais teórica de assuntos inerentes à educação em museus, resumindo-se a uma capacitação a partir da discussão de teorias educacionais e conhecimentos acerca da 
prática de mediação; os referenciais teóricos referentes a ações educativas em museus foram o eixo central do curso de formação do Mast, ressaltando uma aplicação prática da teoria. $\mathrm{Na}$ formação continuada em serviço, as autoras averiguaram que o destaque nos conhecimentos da formação profissional se manteve, de modo que o mediador, com o passar do tempo, estudando, participando de palestras e de reuniões de avaliação, pudesse se apropriar da base da prática educacional em museus. As autoras concluem sobre o processo de formação dos dois museus estudados, destacando que, em ambos os casos,

[...] os saberes da experiência foram fortemente valorizados. O próprio exercício da mediação foi considerado elemento constituinte da formação de um mediador nessas instituições. Isso significa considerar que os saberes que fundamentam o trabalho de um mediador são também adquiridos e aprimorados ao longo do tempo, com a prática, a partir da relação com o público [...] (GOMES; CAZELLI, 2014, p. 15).

O compartilhamento de experiências foi muito importante nos processos de formação ofertados pelo Mast e pelo ECV, haja vista que, com os mediadores mais experientes conduzindo as atividades, a partilha de estratégias de mediação e os diálogos construídos acerca da parte prática da mediação foram facilitadas (GOMES; CAZELLI, 2014).

Outro ponto a ser abordado sobre mediadores de museus, segundo Bailey (2006) e Crespi et al. (2005), está relacionado aos sentimentos, muitas vezes, paradoxais dos próprios mediadores, visto que consideram o trabalho não muito apaixonante, mesmo o julgando envolvente e comprometido com os objetivos da popularização e disseminação da ciência. Os mediadores também não se sentem valorizados economicamente, percebendo-se menosprezados e excluídos dos diálogos em que se discutem as metas e os programas dos museus (BAILEY, 2006; CRESPI et al., 2005). Com essa postura, os museus podem estar perdendo o potencial que a mediação humana possui para tornar as visitas mais educativas e atraente aos visitantes. A formação e a valorização dos mediadores são fundamentais para que a mediação em museus possa abarcar todas as possiblidades inerentes a essa função.

\section{Aspectos metodológicos da investigação}

O estudo proposto, de natureza qualitativa, caracteriza-se como um estudo de caso, tendo se desenvolvido em uma situação natural que, segundo Ludke e André (1986, p. 18) “é rica em dados descritivos, tem um plano aberto e flexível e focaliza a realidade de forma complexa e contextualizada". O caso estudado ocorreu no Instituto Nacional da Mata Atlântica (INMA), localizado na cidade de Santa Teresa, ES, município da região Centro-Serrana, distante cerca de $70 \mathrm{Km}$ da capital do estado do Espírito Santo, Brasil. O espaço corresponde ao mais antigo local dedicado a pesquisas do Bioma Mata Atlântica, fundado pelo naturalista Augusto Ruschi em 1949. Com uma extensão territorial de $8000 \mathrm{~m}^{2}$, abrigou a chácara Anita, depois passou a funcionar como Museu de Biologia Professor Mello Leitão e, na atualidade, como Instituto Nacional da Mata Atlântica, vinculado ao Ministério da Ciência, Tecnologia e Inovação (ROLDI et al., 2016). 
$\mathrm{O}$ atendimento aos grupos no INMA, na visita monitorada, é oferecido de terças às sextas feiras, sendo conduzido por recepcionistas, funcionários terceirizados que conduzem os grupos pelo parque zoobotânico e pelas exposições temporárias e permanentes do instituto. O público predominante são alunos do ensino fundamental, seguido do ensino médio, com procura pouco expressiva de escolas da educação infantil e educação superior do estado do Espírito Santo, principalmente da região metropolitana de Vitória e das cidades localizadas no entorno da cidade de Santa Teresa.

As visitas monitoradas são agendadas previamente. Não havendo a disponibilidade de um recepcionista para acompanhar o grupo, este pode fazer a visitação autônoma no parque, com a supervisão do professor representante da escola. Utilizamos os termos visita monitorada e recepcionistas por serem estes adotados pelo Instituto. Entretanto, no decorrer do estudo utilizamos o termo mediadores para nos referirmos aos recepcionistas do INMA.

Como forma complementar de comunicação com o público, o Instituto dispõe de um vídeo institucional “O Museu da Mata Atlântica”, com duração de sete minutos. Normalmente, antes de iniciada a visita monitorada, os grupos são encaminhados ao auditório para recepção e boas vindas e para a exibição do vídeo. Após assistirem ao vídeo, são conduzidos ao parque zoobotânico.

Atualmente, o INMA conta com cinco recepcionistas terceirizados, com formações variadas, não sendo exigido, para tal função, licenciatura ou bacharelado em Ciências Biológicas, ou áreas afins ou mesmo estar matriculados nesses cursos. Entre as formações, existe um recepcionista com ensino médio, um biólogo bacharel, um estudante de ciências biológicas licenciatura, um estudante de Engenharia Ambiental e um estudante do curso de Letras. As visitas são orientadas segundo um manual existente no Instituto. Assim que os recepcionistas são contratados, recebem o manual para estudo e, depois de aproximadamente trinta dias, acompanhando outros mediadores, começam a conduzir e mediar as visitas. As funções dos recepcionistas, além da mediação humana, são a acolhida na portaria do INMA, o atendimento ao telefone, o agendamento das visitas e o atendimento no pavilhão de ornitologia, devendo estar à disposição para sanar dúvidas dos visitantes. As funções são ocupadas de acordo com uma escala programada mensalmente. Dos cinco recepcionistas, somente três se mostraram receptivos a participar da pesquisa.

Os três recepcionistas que participaram da pesquisa foram: Ana, com 23 anos de idade, exerce a função há três anos e cursa o oitavo período de licenciatura em ciências biológicas na modalidade presencial. Beto ocupa a função de recepcionista há aproximadamente 01 ano, tem 21 anos de idade e cursa o sexto período de engenharia ambiental, na modalidade presencial; Carlos cursa licenciatura em Letras a distância (português/português), atua na instituição há cerca de dois anos e tem 40 anos de idade.

Atendendo aos preceitos formais da ética na pesquisa com seres humanos, conforme a resolução CNS no 196/96 (BRASIL, 1996) e suas complementares, os participantes receberam o termo de consentimento livre e esclarecido, os quais foram lidos e assinados antes da realização do estudo. Os nomes utilizados são fictícios, a fim de preservar as identidades dos sujeitos envolvidos na pesquisa.

Para produção dos dados, observamos, por dez dias, as rotinas e os procedimentos dos mediadores do INMA, com o objetivo de compreender o desempenho de suas funções. Durante esse período, também acompanhamos as visitas monitoradas, momento em que a 
observação sistemática foi importante. Após esse período de observação, realizamos uma entrevista com os três participantes da pesquisa individualmente. A primeira a ser entrevistada foi Ana, seguida de Beto, finalizando com Carlos. A entrevista foi semiestruturada, cujas características são, conforme Triviños (1987), os questionamentos básicos apoiados em teorias e hipóteses que se relacionam ao tema da pesquisa.

Os dados produzidos foram as transcrições das gravações em áudio das entrevistas e os registros das visitas monitoradas realizadas com os mediadores do INMA. Utilizamos também as anotações em diário de campo para complementar as informações transcritas. Os dados oriundos das transcrições e registros em diário de campo foram selecionados e apresentados na análise em forma de episódios. O corpus de análise produzido foi organizado de modo a evidenciar duas dimensões principais que se complementam na prática dos mediadores: a dimensão formativa, relativa aos aspectos relacionados tanto à trajetória de formação quanto às demandas formativas dos sujeitos entrevistados e a dimensão mediacional, que se refere ao papel de mediador exercido por esses sujeitos enquanto recepcionistas no INMA. Essa categorização emergiu das análises e serviu como fio condutor para a organização dos discursos.

Para a discussão dos dados, utilizamos o referencial teórico acerca da mediação humana em museus, com vistas a compreender o caso estudado. A partir do cotejamento dos dados produzidos com o referencial teórico, a análise foi dividida em categorias que abrangem as duas dimensões principais que se complementam na prática dos mediadores, quais sejam: a relação da mediação com a formação acadêmica dos mediadores; princípios que orientam a visita monitorada; o papel do mediador e a formação continuada que o INMA oferece.

\section{Análises dos dados produzidos}

\section{A relação da mediação com a formação acadêmica dos mediadores}

Durante o diálogo, os mediadores se referem basicamente a dois momentos que utilizam como recurso para iniciar a visita monitorada: o vídeo institucional e a história de Augusto Ruschi. A mediadora Ana afirmou que inicia com a história de Augusto Ruschi, Beto e Carlos apresentaram o vídeo institucional como proposta de início da visita monitorada. No entanto, existe um ponto em comum, os três relatam a história do fundador do INMA, antes de efetivamente iniciarem a visita pelo parque zoobotânico.

De acordo com as entrevistas e o acompanhamento das visitas monitoradas, constatamos uma mediação por repetição, partindo do pressuposto de que o visitante não tem conhecimento algum sobre os espaços do INMA. Essa constatação vai ao encontro de Rodari e Merzagora (2007), quando afirmam que o mediador de museus reproduz um roteiro elaborado antecipadamente, em uma mediação por repetição, partindo do pressuposto de que o visitante não tem conhecimento algum sobre a exposição a ser apresentada.

Apesar de possuírem um roteiro estruturado para a organização do percurso da visita monitorada, os três mediadores destacaram, nas entrevistas, que o roteiro é flexibilizado em função dos pontos do trajeto que pretendem enfatizar, quer seja a pedido do professor que 
acompanha a turma visitante, quer seja pela preferência do próprio mediador. Entretanto, essa flexibilização ocorre apenas na ordem de visitação dos pontos estratégicos, porque o discurso se mantém em uma via de mão única, o mediador como locutor e os alunos como ouvintes passivos. Somente a mediadora Ana comentou que escolhe um ponto específico para sanar dúvidas, porém, como ela só concede esse único momento, pode ocorrer que o visitante não se lembre mais da dúvida que teve em pontos anteriores. Os episódios transcritos abaixo demonstram a flexibilização dos pontos estratégicos mencionados pelos mediadores do INMA.

Ana: Ah, não sei, mas geralmente paro para falar de três pontos: O viveirão, os beijaflores e aqui em cima [pavilhão de ornitologia], no viveirão falo de animais silvestres e de todos os tipos, nos beija-flores en falo dos beija-flores, da casa, eu gosto de contar a história da casa e de Santa Teresa [...]. Aqui em cima, a gente consegue tirar as dúvidas que tiveram antes, geralmente.

Beto: Eu enfatizo mais a parte histórica, gosto de valorizar Augusto Ruschi e enfatizo também [bastante] as plantas. Considero importante falar do Ruschi por ele ser o fundador do museu e como conbeço planta, consigo faz̧er ligação com o meio ambiente. Carlos: Olba, en gosto muito de falar sobre Augusto Ruschi, e depois também sobre os animais empalhados, eu gosto muito de chamar a atenção quanto aos animais empalhados pelo fato de alguns estarem em risco de extinção e aí também abordo questões ambientais [...].

Também verificamos nos episódios acima a preocupação dos recepcionistas em uma mediação em busca de refletir sobre o discurso assumido pelo INMA, qual seja: (a) disseminar informações sobre a biodiversidade por intermédio de ações de educação, comunicação científica e museologia; (b) preservar a memória e a obra de Augusto Ruschi, entre outros. Assim, os mediadores assumem claramente seu papel como interlocutores entre o INMA e o público, como proposto por Marandino (2008, p. 28) para os quais os mediadores desempenham "papel central, dado que são eles que concretizam a comunicação da instituição com o público e propiciam o diálogo com os visitantes acerca das questões presentes no museu, dando-lhes novos significados". Notamos uma preocupação em trazer a memória de Augusto Ruschi, enfatizando a importância do naturalista para a conservação ambiental em Santa Teresa e em todo o Espírito Santo.

Importante destacar a preocupação em abordar questões ambientais durante a visita monitorada, como enfatizado por Carlos, bem como a preocupação dos três mediadores, mais fortemente em Beto e Carlos, em reproduzir o roteiro que o instituto oferece. Essa preocupação pode ter decorrido da falta de domínio dos conceitos biológicos, conforme revelado por Ana. É possível constatar que Ana possui maior flexibilidade na condução da atividade, indo além das explicações contidas no roteiro. Ana, que é estudante do curso de ciências biológicas, conduz uma monitoria mais diversificada e mais crítica pelo parque zoobotânico, visto que conduz a visita instigando, estabelecendo comparações entre peças em exposição, permitindo que o visitante pergunte tópicos variados. Citamos como exemplo, quando Ana estava mediando um grupo em um local denominado jardim rupestre, um aluno questionou sobre polinização, a mediadora, então, aproveitou para destacar a contribuição desses animais para o meio ambiente, bem como para os seres humanos, lembrando que a polinização garante 
a reprodução de plantas, auxiliando, consequentemente, na produção de alimentos. Beto é estudante de engenharia ambiental e enfatiza a parte botânica. Carlos, estudante do curso de Letras, sente-se seguro na parte histórica e na descrição sumária do ambiente. Tais evidências foram flagradas nas entrevistas aplicadas aos mediadores e nas anotações em diário de campo, capturadas no transcurso do acompanhamento das visitas.

Caffagni (2010) corrobora com a realidade descrita acima, quando aponta que os mediadores dos museus de ciência, normalmente, são estudantes de biologia, química, física, geografia e áreas afins. No caso do INMA (um museu de biologia), Ana é da área específica propriamente dita (ciências biológicas) e os outros dois são de áreas afins, cujas matrizes curriculares não abrangem abordagens das características gerais dos seres vivos, conteúdo abordado no monitoramento das visitas ao parque zoobotânico do INMA, por exemplo. Pelo exposto, consideramos a formação em ciências biológicas como facilitadora na condução da visita monitorada, visto que o parque zoobotânico do INMA requer conhecimento sobre os seres vivos, principalmente sobre plantas e animais, se levarmos em consideração que o mediador deve ter a compreensão segura das exposições para conseguir adequar seu diálogo às diferentes idades, níveis de conhecimento e de interesse (MORA, 2007).

\section{Princípios que orientam a visita monitorada}

Questionados em relação aos princípios que orientam as visitas monitoradas no INMA, os mediadores entrevistados explicaram que as estratégias de comunicação têm por objetivo chamar a atenção dos alunos ou de adequar o conteúdo do roteiro explicativo ao nível de escolaridade do grupo monitorado. Foi possível observar o propósito de adequação do discurso à diversidade dos visitantes, mesclando-se o rigor conceitual do conteúdo com uma apresentação apropriada à idade e/ou ao grau de escolaridade. Os episódios colhidos e apresentados refletem essa constatação.

Ana: Tem diferenças com grupos menores dá pra chamar atenção tipo meninos e tal, e se é um grupo de faculdade a gente fala mais sério e depende muito, se o grupo tá prestando bastante atenção é mais sério, mais tranquilo, a gente brinca e coisa e tal.

Beto: Então, procuro ver o grau de escolaridade assim, às vezes pergunto ao professor mais ou menos o que ele quer que trabalhe, e depois, é... tento adaptar, mas tenho muita dificuldade em simplificar para os pequenos, às vezes acho que falo muito técnico pra eles. Carlos: Porque não adianta vir aqui fazer apenas um passeio e sair daqui sem informação. Então é [pausa] o que me foi passado, eu sempre falo isto para eles, antes da visitação, quando eu me apresento, eu tenho maior praz̧er em passar pra eles, só que eu quero a colaboração deles. Então eu peço que desliguem os celulares, que não fiquem conversando.

Apesar da aproximação, contudo, notamos pouca interação com o grupo. Beto reconhece que tenta interagir por meio de questionamentos, e realmente o faz, entretanto, não concede o devido tempo para os alunos responderem, ficando a pergunta mais como um direcionamento para sua apresentação do que para a interação propriamente dita. Assim, quando a mediação é pensada de modo que os mediadores ensinem pela experiência e prática, sabendo 
formular apropriadamente a pergunta a fim de detalhar e enriquecer a experiência do visitante (JOHNSON, 2007), o objetivo não é alcançado. Na ação intencional de perguntar, o objetivo da ação é muito importante, evidenciando o pretendido. No caso dos mediadores entrevistados, como exposto anteriormente, a pergunta tem o propósito de manter a interlocução, mas nem sempre eles conseguem o pretendido. O discurso está centrado na transmissão do conteúdo. O episódio a seguir ilustra uma das perguntas realizadas por Beto durante a visita monitorada, com ele mesmo respondendo, imediatamente após, ao questionamento. "Vocês sabem que espécie de planta é essa aqui? Essa é uma palmeira imperial." [Beto].

\section{O papel do mediador e a formação continuada que o INMA oferece}

Durante as entrevistas, conseguimos destacar que os recepcionistas se percebem como interlocutores entre O INMA e o público. Apesar dessa percepção, não há um consenso entre eles acerca do seu papel como mediadores de museus. Ora se veem como educadores ambientais, ora se identificam como guias de parque, demonstrando a falta de uma concepção mais objetiva de qual seja o papel de um mediador de museus de ciência, em especial do INMA, que tem um apelo ecológico, por ser um museu de biologia. Talvez essa falta de consenso decorra dos vários pontos de vista acerca do papel que um mediador de museus deve desempenhar (GOMES; CAZELLI, 2016). Ana foi a que demonstrou uma ideia mais aproximada da função de mediadora de museus, conforme descrito na literatura, cuja mediação em museus aponta para diversos níveis de diálogo: "entre o público e as exposições; entre os sujeitos e o saber; entre a arte, a ciência, a história e a sociedade" (GOMES; CASELLI, 2016, p. 4). Os episódios a seguir demonstram a falta de consenso anteriormente citada.

Ana: Tem um que fala assim, eu não sou educador ambiental, eu não estou aqui para fazer um trabalho de educador ambiental, estou só para acompanhar o grupo [...].

Beto: Às vezes a gente se reúne e fala, ah vamos fazer alguma diferente para os grupos. Tem sempre aquele que fala, eu sou apenas um recepcionista, e não quer fazer.

Carlos: E outra coisa, ai fica aquela questão, poxa, o que en sou aqui, en sou recepcionista ou eu sou "um educador ambiental" né. Não sei o que somos.

Se atentarmos para as especificidades do INMA, o mediador deve ser sensível a vários fatores, por se tratar de um museu de biologia, questões ambientais irão surgir e os mediadores devem estar preparados para tais situações. Não estamos querendo afirmar que os mediadores do INMA devem atuar como educadores ambientais, no entanto, em determinadas situações, podem demandar de conhecimentos inerentes a tal função. Para isso, se faz necessária uma formação singular visando ao entendimento das especificidades do INMA.

A falta de percepção do papel do mediador é corroborada pelo modelo atual do quadro funcional do instituto, em que recepcionistas são deslocadas para fazer a mediação em museus (visita monitorada). Desse remanejamento emergem preocupações trabalhistas, ficando os recepcionistas restritos a questões contratuais, de modo a não caracterizar um eventual desvio de função. Tais fatores nos remetem a Bailey (2006) e Crespi et al. (2005), para quem os próprios mediadores têm sentimentos contraditórios em relação ao seu trabalho, mesmo 
não se revelando apaixonados pelo que fazem, consideram-no envolvente, por outro lado se sentem desvalorizados em seus espaços de trabalho. Observamos que os mediadores do INMA não se sentem valorizados em seu trabalho, conforme foi constatado no decorrer do acompanhamento de suas rotinas.

Também foi observado um fato unânime entre os três mediadores, justificado pela falta de consenso sobre o papel do mediador na instituição. Como eles próprios não conseguem se identificar com a instituição, acreditam que uma formação continuada poderia auxiliá-los. Para atuar como recepcionista do INMA, a formação se restringe ao recebimento do roteiro de visitação e ao acompanhamento de mediadores mais experientes por cerca de trinta dias. Após esse período de aclimatação, passam a desempenhar sua função sem supervisão ou acompanhamento. Esse fato faz da troca de experiências entre eles uma exigência para o desempenho da função. Outros fatores que os auxiliam nessa formação inicial são a busca por informações na rede mundial de computadores e nos setores de pesquisa do INMA, como o setor de zoologia e da botânica. Os episódios abaixo demonstram como os mediadores tentam completar sua formação, por meio da pesquisa.

Ana: Geralmente só da faculdade mesmo... alguma informação que a gente pegou na internet ou com o pessoal da zoologia ou do herbário, a gente geralmente usa com o visitante avulso, com o grupo a gente usa mais o monitoramento mesmo.

Beto: Não tive formação nenbuma quando entrei aqui no museu, apenas recebi o monitoramento pra decorar e acompanhei outros grupos. Quando tenho dúvida procuro na internet ou procuro conversar com a Ana, porque tenho mais afinidade com ela.

Carlos: Não tive formação, a gente conversa, sobre o comportamento dos alunos, sobre as falhas, sobre as melhorias, o que pode ser feito e tal, mas eu acho que tá faltando muito apoio da parte lá de cima, porque as vezes a gente se sente assim, muito largado. Falta uma reciclagem, falta uma visita [...].

Foi possível observar, ainda, a falta de investimento na formação dos mediadores do INMA, sendo negada a eles a possibilidade de desenvolvimento na função e mesmo a construção de uma identidade como profissional qualificado a executar função considerada essencial na configuração educacional, mais ampla, dos museus atualmente (RODARI; MERZAGORA, 2007). Nossos entrevistados se esforçam no desempenho de um trabalho que se aproxima de um dos objetivos dos museus na atualidade, o qual diz respeito à ampla interação desses espaços com a sociedade, mesmo sem o aporte teórico oferecido pela instituição. Queiroz (2013) reforça essa ideia, evidenciando que a formação inicial e continuada dos mediadores de museus não deve ser restrita, apesar de importante, aos aspectos técnicos. A mesma autora argumenta que para transformar a mediação de museus, em uma prática de diálogo com o visitante, é preciso oferecer formação continuada em serviço a seus mediadores.

Se compararmos a formação que os mediadores do INMA possuem, além das buscas pessoais por conhecimento sobre o parque zoobotânico do instituto, será possível constatar que ela contém as deficiências apontadas por Rodari e Merzagora (2007), quando pesquisaram como os museus de ciências europeus formam seus profissionais, com destaque para três deficiências, entre as outras identificadas pelos autores, quais sejam: (1) dificilmente a capacitação inclui aporte teórico sobre educação não formal bem como a teoria da comunicação da ciência; 
(2) não são capacitados para explorar os objetivos, o impacto e os resultados do seu trabalho;

(3) não são preparados para coletar e analisar as reações do público.

Diante do exposto, a formação de mediadores do INMA deve ser centrada na construção do diálogo que pode ser compartilhado entre os profissionais da instituição e entre eles e profissionais de outros museus para trocas interculturais e experiências, bem como para discussão e aprofundamento de aportes teóricos em sua área específica. Como averiguado por Gomes e Cazelli (2014), em um estudo acerca da formação de mediadores no Mast e no ECV, entre outros elementos, o compartilhamento de experiências foi muito importante nos processos de formação estudados no Mast e no ECV, pois, com os mediadores mais experientes conduzindo as atividades, facilitou-se a partilha de estratégias de mediação e os diálogos construídos acerca da parte prática da mediação.

Foi observada certa nostalgia em dois dos mediadores, os quais fizeram alusão a um passado no qual havia mais ações diversificadas voltadas ao público, ações denominadas de práticas educativas, sugerindo que, antes, a instituição era composta por um setor pedagógico mais dinâmico e organizado, como consta nos episódios a seguir.

Ana: E na época que existia setor educativo, a gente fazia também palestra extra, tinha o museu de encantos. Hoje nós só monitoramos.

Carlos: Dia das crianças, por exemplo, fazíamos uma espécie de teatro né, tinha o cacador, tinha o lenhador, era muito interessante.

Os entrevistados remetem a um passado em que o instituto parece ter tido maior desenvolvimento de ações educativas e culturais, promovidas pela instituição museológica para mais se aproximar das escolas. Assim, no caso do INMA, atividades implementadas junto às exposições e ao parque zoobotânico envolvem esses profissionais, os quais, ainda que não participem da concepção das exposições, atuam junto ao público.

O termo formação, durante as entrevistas e de acordo com as anotações em diário de campo, foi muitas vezes utilizado pelos mediadores do INMA, evidenciando mais fortemente o anseio por qualificação para o desempenho da função. No entanto, a expressão mediação, não foi utilizada, mesmo com a pesquisadora se referindo à monitoria das visitas como uma mediação humana. Durante as observações, foi percebido que os entrevistados desconhecem os teóricos que se dedicam ao estudo de mediação em museus, isso pode explicar a não apropriação do termo mediação humana. Assim, inferimos que eles desconhecem o que é mediação humana em museus de acordo com o referencial teórico adotado nesta pesquisa e isso reflete no não entendimento do seu papel no INMA.

\section{Considerações finais}

Foi possível identificar uma tendência dos mediadores em reproduzir o roteiro que o INMA oferece. Isso faz com que se torne repetitiva para os alunos que desejam liberdade para explorar ambientes com que possuam maior afinidade. No entanto, apesar da preocupação em reproduzir o roteiro, os recepcionistas buscam uma adaptação do discurso de acordo com a série/idade dos visitantes. 
O anseio por uma formação continuada ficou marcante durante a aplicação das entrevistas, talvez reforçado pela não compreensão do real papel de um mediador de museus, visto que eles são contratados como recepcionistas e deslocados para realizar a mediação das visitas monitoradas, ficando restritos a questões contratuais para a não caracterização de desvio de função. No entanto, analisando as visitas monitoradas, concluímos que os recepcionistas são mediadores de museus, mesmo que eles próprios não tenham um consenso a esse respeito. Isso, porque eles são funcionários e ocupam lugar definido pela instituição como condutores das visitas monitoradas, utilizando-se de recursos e estratégias disponíveis para este fim, com o objetivo de levar aos grupos guiados conhecimentos acerca da história da instituição e de seu fundador, das pesquisas realizadas, bem como conceitos biológicos e a diversidade dos seres vivos presentes no parque zoobotânico. O ideal seria que o mediador compusesse a equipe de educadores que participam da criação e da tomada de decisões junto de outros setores do museu.

No que se refere à oferta de formação continuada em serviço, conforme identificada nessa pesquisa, o INMA poderia oferecer tal formação, utilizando-se dos diversos pesquisadores da instituição que desenvolvem pesquisas com plantas e animais, visando a preencher essa lacuna. Devemos lembrar que essa formação é apenas um dos aspectos que devem ser abordados na formação geral dos mediadores. O INMA também poderia estabelecer encontros mensais entre os recepcionistas para discussão de artigos científicos relacionados à mediação em museus, bem como para troca de experiências. Tais encontros além de ajudá-los na compreensão do papel de um mediador de museus, poderia contribuir para o fortalecimento do grupo e para que eles se reconheçam como mediadores de um museu de ciência. Seria interessante se os mediadores visitassem outros espaços museais, a fim de verificar outras formas de mediação, diferentes das praticadas ali.

Para além desse estudo no INMA, é possível perceber a falta de investimento em formação para mediadores de museus, de modo geral. Esses profissionais, como já destacado, em sua maioria, são estudantes universitários que, posteriormente, poderão atuar como professores na educação formal. Essa formação poderá auxiliá-los na construção de suas profissões tanto em espaços não formais quanto em espaços formais de educação. Esses saberes podem promover habilidades pedagógicas diversificadas, favorecendo a tais profissionais formas criativas de motivar seus alunos a utilizar espaços educativos não formais, como os museus de ciência, na busca da divulgação científica e por contágio, avançar na alfabetização científica.

O INMA tem grande potencial para se tornar um espaço de educação não formal, cujos mediadores possam atrair e motivar o visitante, por meio das atividades interativas, provocando o visitante em busca de respostas, para tal, precisam se conscientizar da importância de sua função social na aprendizagem e de seu papel no instituto. $O$ fato é que se deve dar a devida importância às mediações em museus de ciência, considerando-as a partir de seu potencial na divulgação científica e no ensino de ciências.

Este trabalho teve por objetivo analisar como a mediação humana nas visitas monitoradas ocorre no Instituto Nacional da Mata Atlântica e quais as aspirações dos mediadores em questão. Acreditamos tê-lo atendido quando exploramos seu desejo por uma melhor formação continuada e discutimos como eles conduzem as visitas monitoradas e seus anseios acerca de quem são e qual seu verdadeiro papel no instituto, de modo a enfatizar a relevância da mediação humana em espaços museais. 


\section{Referências}

ALMEIDA, M. A. Mediações da cultura e da informação: perspectivas sociais, políticas e epistemológicas. Tendências da Pesquisa Brasileira em Ciência da Informação, João Pessoa, v. 1, n. 1, p. 1-24, 2008.

BAILEY, E. B. Researching museum educators' perceptions of their roles, identity, and practice. Journal of Museum Education, Washington, v. 31 n. 3, p. 175-197, 2006. DOI: https://doi.org/10.1080/10598650.2006.11510545.

BRAGA, J. S. A mediação em museus de ciências da Universidade de São Paulo: a experiência no Museu de Anatomia Veterinária Dr. Plínio Pinto e Silva e na Estação Ciência. 2012. 196 f. Dissertação (Mestrado em Ciência da Informação) - Escola de Comunicações e Artes, Universidade de São Paulo. São Paulo, 2012. Disponível em: http://www.teses.usp.br/ teses/disponiveis/27/27151/tde-17042013-111942/pt-br.php. Acesso em: 2 mar. 2018.

BRASIL. Ministério da Saúde. Resolução no 196, de 10 de outrubro de 1996. Brasília: CNS, 1996.

CAFFAGNI, C. W. A. O estudo das analogias utilizadas como recurso didático por monitores em um centro de ciência e tecnologia de São Paulo - SP. 2010. 207 f.

Dissertação (Mestrado em Educação) - Faculdade de Educação, Universidade de São Paulo, São Paulo, 2010.

CRESPI, M.; GOUTHIER, D.; MANZOLI, F.; RODARI, P. L'immagine dela scienza nei bambini e negli adolescenti: il ruolo dei musei. In: PITRELLI, N.; STURLONI, G. (ed.). La stella nuova. Milano: Polimetrica, 2005. p. 49-58.

DAVALLON, J. A mediação: a comunicação em processo? Prisma.com: revista de ciências e tecnologias da informação e comunicação, Porto, n. 4, jun, 2007. Disponível em: http://ojs. letras.up.pt/index.php/prismacom/article/view/2100. Acesso em: 27 mar. 2018.

GOMES, I; CAZELLI, S. Formação de mediadores em museus de ciência: diálogos entre a educação formal e não formal. Educação Online, Rio de Janeiro, n. 16, p. 1-22, 2014.

GOMES, I; CAZELLI, S. Formação de mediadores em museus de ciência: saberes e práticas. Ensaio, Belo Horizonte, v.18, n. 1, p. 23-46, 2016. DOI: https://doi.org/10.1590/198321172016180102.

JOHNSON, C. Capacitação de mediadores em centros de ciências: reflexões sobre o techniquest. In: MASSARANI, L.; MERZAGORA, M.; RODARI, P. (org.). Diálogos \& ciência: mediação em museus e centros de ciência. Rio de Janeiro: Museu da Vida: Casa de Oswaldo Cruz, 2007. p. 31-37.

LÜDKE, M.; ANDRÉ, M. E. D. A. Pesquisa em educação: abordagens qualitativas.

São Paulo: EPU, 1986.

MARANDINO, M. (org). Educação em museus: a mediação em foco. São Paulo: Greenf: FEUSP, 2008. 
MARTÍN-BARBERO, J. Dos meios às mediações: comunicação, cultura e hegemonia. Rio de Janeiro: Editora UFRJ, 1997.

MORA, M. C. S. Diversos enfoques sobre as visitas guiadas nos museus de ciência. In: MASSARANI, L.; MERZAGORA, M.; RODARI, P. (org.). Diálogos \& ciência: mediação em museus e centros de ciência. Rio de Janeiro: Museu da Vida: Casa de Oswaldo Cruz, 2007. p. 22-27.

QUEIROZ, G. R.P.C. Formação de mediadores para museus em situações educacionais ampliadas: saberes da mediação e desenvolvimento profissional. Ensino em Re-Vista, Uberlândia, v. 20, n. 1, p. 149-162, jan./jun. 2013. Disponível em: http://www.seer.ufu.br/ index.php/emrevista/article/view/23219. Acesso em: 1 jun. 2018.

RODARI, P.; MERZAGORA, M. Mediadores em museus e centros de ciência: status, papéis e treinamento: uma visão geral europeia. In: MASSARANI, L.; MERZAGORA, M.; RODARI, P. (org.). Diálogos \& ciência: mediação em museus e centros de ciência. Rio de Janeiro: Museu da Vida: Casa de Oswaldo Cruz, 2007. p. 8-20.

ROLDI, M. M. C. et al. Projeto jovens pesquisadores: ensino de biologia e divulgação científica em um espaço não formal de educação em Santa Teresa no Espírito Santo. Revista da SBEnBio, Niteroi, n. 9, p. 574-584. 2016. Disponível em: http://www.sbenbio.org. br/2017/03/renbio-edicao-9/. Acesso em: 07 mai. 2018.

TRIVIÑOS, A. N. S. Introdução em ciências sociais: a pesquisa qualitativa em educação. São Paulo: Atlas, 1987.

Recebido em: 19/08/2018. Aceito em: 09/06/2019

Contato: Instituto Federal de Educacão, Ciência e Tecnologia do Espirito Santo, Rua. R. Barão de Mauá, 30, Jucutuquara, Vitória, ES, 29040-860, Brasil. 